\title{
Political Advertising and Media: Insights from a Multicultural Society
}

\author{
Azizul Yadi Yaakop \\ Siti Falindah Padlee \\ Kalsitinoor Set \\ Munir Salleh \\ School of Maritime Business and Management \\ Universiti Malaysia Terengganu \\ azizul_yadi@umt.edu.my
}

\section{Doi:10.5901/mjss.2014.v5n7p510}

\begin{abstract}
During the past a few general elections in Malaysia, public witnessed changes in political campaigns with the use of advertisements not only on the mainstream television and in the newspapers, but also in other form of online media like websites. In the recent $13^{\text {th }}$ General Election the use of the social media was even aggressive and widespread. This study was conducted to compare voters' advertising perceptions and attitudes toward political advertising in Malaysia, delivered through the traditional media i.e. print and television and the modern-day social media, by using a number of variables. The comparisons were analyzed from two important demographic factors in an election which are (i) location of the voters (i.e. city, surburban area and rural area) and (ii) race (i.e. Malay, Chinese, Indian and other Bumiputras). The study was conducted for a period of one month following the dissolution of the Parliament on $4^{\text {th }}$ April 2013. The implications of the study focus on the consumers' perceptual shift in terms of the use of media in propagating political parties in the recent general election in Malaysia. The limitations of the study are also discussed.
\end{abstract}

Keywords: Advertising, attitudes towards advertising, political advertising, Malaysia $13^{\text {th }}$ General Election

\section{Introduction}

For the past several decades, advertising has been a subject of business marketing success on one side as well as an issue of societal ethical clashes on the other. In most cases, however, the trade-off effect is subtle to marketing practitioners and advertisers. In contrast, advertising is seen as a discipline with social and cultural repercussions in the eyes of the general public (Sandage and Leckenby 1980). Without doubt, advertising was, and still is meant to create attention and to bring fresh ideas for public consumption. Advertising is aimed at changing perceptions or attitudes by means of mass communications. This accurately corresponds to its Latin root, advetere, i.e. it communicates information for the purpose of "turning the mind toward" purchase (Rossiter and Percy 1996). Indeed, it is one of the marketing tools employed to effect favourable purchase behaviour (Ambler 2000; Colley 1961; Petty and Cacioppo 1986). In spite of advertising's known practical sales consequences, a major indictment of advertising reached its peak when it was criticized by several humanities and social sciences scholars for having unintended consequences which related to its influential emphasis on materialism, cynicism, irrationality, selfishness, anxiety, social competitiveness, sexual preoccupation, powerlessness and/or a loss of self-respect (Pollay 1986; Pollay 1987).

Like any kinds of advertising, political advertising also faces the same issue. Political advertising is advertising that attempts to influence upon a matter of extensive political debate (Political election advertising: What is Political advertising). It includes advertising or marketing communication with community about a political party representative or candidate, advertising about political issue or issue of public interest and advertising in relation to government political. In spite of "no rule" ruling to the content and form of political advertising, it has become increasingly essential to campaign strategy. As a matter of fact, the current state of political advertising has been considered within the world of commercial advertising (Greening \& Gray, 1994). Political advertising does not exist occasionally, the presence is apparently ubiquitous. Similar to other parts of the world, political advertising is more prevalent during the elections in Malaysia's political scene in order to raise awareness or encourage a change in voters' behaviour or perceptions. According to Jamieson and Campbell (2000), mass media has an important role to affect the voters' decision to vote due to its 
informative role. Media is also of paramount important to inform voters about candidates' positions and affecting the 'preferences and participatory ethos of the electorate (Ansolabehere \& Iyengar, 1995).

At this point, some preliminary questions need to be answered in relations to consumers' perceptions about political advertising. Firstly, what are Malaysians voters' perceptions and attitudes towards political advertising? And secondly, do demographic factors have impacts on these perceptions? Therefore, in this study, we are interested to understand Malaysian voters' perceptions and attitudes towards political advertising particularly looking at the differences that may present due to differences in voters' demographic backgrounds.

\section{Significance of Study}

In Malaysia's political scene, political advertising have been practiced since the 1960's. In 1969 election, the use of printed media such as national newspapers to disseminate information to voters was crucial (Ratnam and Milne, 1970). In the United States, voters witnessed changes in political campaigns since the $11^{\text {th }}$ general election when political advertisements appeared not only on newspapers and the television, but in other forms of media. Likewise, the contemporary political campaigns in Malaysia now have evolved dramatically from mainly relying on using traditional media including mainstream media (electronic and printed) to advertise their agenda to using the World Wide Web. To the practitioners, this demonstrates how mass media plays an important role in changing political landscape in Malaysia. However, from the voters' perspective, do they think that the political advertising in the mass media has effectively played its part to win any political election? This is the question that needs answers prior jumping into any bandwagon.

\section{Literature}

\subsection{Political advertising on the television}

In general, television is a medium known for its ability to evoke feelings through the use of motions, colours, sound and special effects. It is not surprising that television advertising is placed near to the attribute "stimulating emotions" in Leong et al.'s (1998) perceptual mapping. The authors suggested that television advertising has the ability to arouse emotion and to entertain viewers, and this has made it superior to the other advertising media. In fact, mixed emotions of enjoyment and dignity stimulated by television ads influenced people's overall attitudes towards advertising (Shavitt et al. 1998). For example, one of the functions of television which was found to be highly inter-correlated with people's attitudes towards television advertising was its entertainment function; in particular, people found television advertisements were fun to watch and a lot of the ads were funny or clever (Alwitt and Prabhaker 1992). Recent analysis by Tan and Chia (2007) also upheld this notion that the hedonic/pleasure function of advertising was positive and significant in predicting attitudes towards television advertising.

In political scene, television has played a major role in campaigns for a long time. Although the use of television in political campaigns has changed significantly since it was first introduced in the early 1950's, it has proven to be one of the most important and expensive strategies that candidates employ. Television affects how the general public perceives candidates and may be the most effective campaign tool. Numerous studies have shown that voters exposed to political advertising on television retained knowledge and information about the candidates, such as their name, stance on issues, or image attributes (Atkin \& Heald, 1976; Kaid, 2002; Valentino et al., 2004). Exposure to political ads is also effective in influencing viewers' evaluations of the candidates (Kahn \& Geer, 1994; Kaid, Chanslor, \& Hovind, 1992; Kaid \& Sanders, 1978; Tinkham \& Weaver-Lariscy, 1993) as well as voters' perceptions of the political process in general and their political behavior (Ansolabehere \& lyengar, 1995; Kaid et al., 1992).

\subsection{Political advertising on printed media}

Even though researches on the effectiveness of print media in promoting political are somewhat limited, generally for many consumers, newspapers are their primary source of information, be it for commercial or political. Print media is also seen as not intrusive like radio and television, and they generally require some effort on the part of the reader for advertising massage to have an impact. For this reason, print media are often referred to as high-involvement media. This finding is similar to previous research showing that online advertising has the ability to deliver rich information and detail, which is also in line with other traditional media such as print media (Schlosser and Shavitt 1999; Ducoffe 1996; Brackett and Carr 2001; Lei 2000; Yaakop, A et. al 2013). Leong et al. (1998) carried out a cluster analysis and produced a dendrogram that suggested that attributes such as creating brand/product/corporate awareness, communicating 
product/brand image and communicating corporate image are the best to characterize the press (or print advertising media). Even adolescents at the tender ages of 14 to 19 preferred to read newspapers to find out about news and current events (La Ferle et al. 2000).

The use of printed media in disseminating information to voters in Malaysia can be traced back in 1969. During that time, magazines and newspapers were the only major media available to campaigners. Its popularity was, however, declining with the introduction of television to propagate political issues. But despite the competition from the television, print media has remained important media to political campaigners because of its high-involvement impact.

\subsection{Political advertising on the social media}

Social networking sites such as Facebook and Twitter have recently offered a new outlet for political candidates to reach out to the voting population. Since this method is relatively new and able to draw mass attentions especially the youth and new generation of voters, they are being used by many campaigners. So it is not surprising that social media went from being virtually unknown in the realm of Malaysian politics in the past few general elections to a budding form of political communication during the recent one. In an advanced country like the United States, Web sites have been used by candidates for fund-raising and communicating directly with supporters for so many years. However, the recent 2013 general election showed that the social media has become increasingly popular platforms for political participation (Quily, 2008; A. Smith, 2009; Vitak et al., 2009). In fact, the use of Facebook for political purposes was so significant that it caused major headlines in news (Rawlinson, 2007).

It is well known that politicians view social networking as a legitimate form of publicity and that they use it accordingly. However, to what extent do voters make full use of political advertising on Facebook? In this regard, we should consider the potential impact of voters' perceptions to their attitudes towards political advertising as they are portrayed in Facebook. Analyzing Facebook content and the extent to which it adheres to such portrayals may both indicate how pervasive such stereotypes are in social media and serve as a first step to future studies of the effects of such portrayals. Although the use of Facebook is increasingly popular, Yaakop, A. et al. (2013) argued that consumers have concerns about the credibility of Facebook to disseminate truthful information. Yaakop, A \& Hemsley-Brown, J, (2013), however, posited consumers' attitudes towards internet advertising are influenced by the capability of internet advertising to ring and entertainment.

Broadly, the focus of this research is to understand the perceptions of voters of the various uses of media for political advertising and to investigate how they relate to the respondents' overall attitude towards political advertising. This will involve testing a set of predictive variables in relation to the attitude of political advertising, by identifying and comparing the factors that influence consumer attitudes toward political advertising measured through the variables of advertising perceptions of product information (PI) and hedonic / pleasure (HP) during the $13^{\text {th }}$ General Election.

\section{Research Methodology}

This study aims to examine and compare the perceptions and attitudes of Malaysian voters' towards political advertising delivered through three different media in print, television and the social media. The questionnaire of the study consists of five sections. The first section is about measuring respondents' perceptions towards political advertising on the television, printed media and the social media. The next three sections are about measuring respondents' attitudes towards political advertising on the television, printed media and the social media, respectively. The final section consists of multiple questions regarding respondents' demographic profile.

In section one, four constructs were developed to measure political advertising perceptions using 5 items for each construct on a 5-point Likert scale (e.g. 1 - strongly agree to 5 - strongly disagree). The variables used were product information (PI); to measure individual's beliefs about advertising as a valuable source of information for products or services. Secondly, social role/image; to describe individual's beliefs about advertising that reflect and shape his/her personal image as well as the image of other external subjects. Thirdly, hedonic/pleasure; a variable that encompasses individual's beliefs about advertising in terms of it being entertaining, amusing and pleasurable. And finally, falsity/no sense; which explains the individual's beliefs about advertising as a source of manipulation, exaggeration or misleading information.

Meanwhile, in the section of measuring political advertising attitudes, three items were measured the construct. The items of measuring attitudes using semantic differential scales with 7-point scale (e.g. 1 - good to 7 - not good). All the items in the questionnaire were developed based on Petrovici and Marinov (2007) and Yaakop, A. and HemsleyBrown, J. (2013). 
The data collection was conducted via surveymonkey.com and it was carried out for a period of one month following the dissolution of the Malaysian Parliament on $4^{\text {th }}$ April 2013. During this period, the campaigns from political parties participated were very aggressive and the use of the media was employed to reach the audience. The survey was posted in the Facebook and those respondents interested to follow the survey could click on the survey's link and would be directed to the survey. All information provided by respondents was kept confidential. A total of 266 useable set of questionnaires were collected and all data collected went through a series of analyses.

\section{Results}

\subsection{Respondent profile}

Based on the Table 1, participation from female respondents were higher than male respondents which contribute to 72 percent and 28 percent, respectively. Majority of respondents' age were range between 21-30 years old (65 percent), followed by 31-40 years old (16 percent) and 20 and below years old (9 percent). Malay ethnic contributes to the highest ethnic composition in Malaysia to participate (77 percent), followed by Chinese (16 percent) and Indian and Bumiputra with percentage of 3 percent and 1 percent, respectively. Most respondents were Diploma and Degree holder with percentage of 56 percent. Respondents with postgraduate degree and secondary school contribute 22 and 19 percent, respectively. Respondents live in city were with the highest participation 42 percent compared to surburban and rural area, 19 percent and 36 percent respectively.

Table 1: Respondent Profile

\begin{tabular}{|l|c|c|}
\hline Category & Frequency & Percentage of total \\
\hline Sex (N =266) & 75 & \\
Male & 191 & 28 \\
Female & & 72 \\
Age (N = 266) & 24 & \\
20 and below & 174 & 9 \\
$21-30$ & 43 & 16 \\
$31-40$ & 17 & 6 \\
$41-50$ & 1 & 1 \\
$51-60$ & 2 & 1 \\
61 or older & 5 & 2 \\
Missing & & \\
Ethicity (N = 266) & 206 & 77 \\
Malay & 43 & 16 \\
Chinese & 8 & 3 \\
Indian & 3 & 1 \\
Other bumiputera & 6 & 3 \\
Missing & & \\
Highest education level (N = 266) & 0 & 0 \\
Completed primary school & 51 & 19 \\
Completed secondary school & 150 & 56 \\
Completed diploma/degree & 58 & 22 \\
Completed postgraduate degree & 7 & 3 \\
Missing & & \\
Residential are (N = 266) & 112 & 42 \\
City area & 52 & 19 \\
Suburban residential & 95 & 36 \\
Rural area (village) & 7 & 3 \\
Missing & & \\
\hline
\end{tabular}

\subsection{Descriptive Analysis}

Table 2 presents the mean scores, standard deviation (SD), skewness and kurtosis values of advertising beliefs based on respondents' experiences with political advertising in printed media. From the table, the mean scores for political advertising on printed media range from 2.42 to 3.19 and standard deviation from 0.58 to 0.83 . On the whole, the 
hedonic/pleasure dimension recorded the highest overall mean score (Mean $=3.19, S D=0.73$ ) as compared to the other dimensions (social role/image: Mean $=2.70, S D=0.66$; product information: Mean $=2.61, S D=0.83$; falsity/no sense: Mean $=2.42, S D=0.58$ ). Table 2 also reveals skewness and kurtosis values that indicate non-violation of the normality assumption.

Table 2: Political advertising in printed media scores

\begin{tabular}{|l|c|c|c|c|c|c|c|}
\hline \multirow{2}{*}{} & $\mathrm{N}$ & Mean & Std. Deviation & \multicolumn{2}{|c|}{ Skewness } & \multicolumn{2}{|c|}{ Kurtosis } \\
\cline { 2 - 8 } & Statistic & Statistic & Statistic & Statistic & Std. Error & Statistic & Std. Error \\
\hline Product information & 266 & 2.61 & .831 & .621 & .149 & .412 & .298 \\
Social role/image & 266 & 2.70 & .658 & .395 & .149 & .392 & .298 \\
Hedonic/pleasure & 266 & 3.19 & .733 & .335 & .149 & -.300 & .298 \\
Falsity/no sense & 266 & 2.42 & .582 & .388 & .149 & .031 & .298 \\
Valid N (listwise) & 266 & & & & & & \\
\hline
\end{tabular}

The mean scores, standard deviation (SD), skewness and kurtosis values of political advertising perceptions according to respondents' experiences with political advertsingoon the television are presented in Table 3. From the table, the mean scores for political advertising perceptions were recorded from 2.42 to 3.17 with standard deviation from 0.61 to 0.94 . Again, the hedonic/pleasure dimension recorded the highest overall mean score (Mean $=3.17, S D=0.84)$. The normality test was carried out via the inspection of skewness and kurtosis values and revealed no major deviations from a normal distribution. The values of skewness and kurtosis are also presented in Table 3.

Table 3: Political advertising on the television scores

\begin{tabular}{|l|c|c|c|c|c|c|c|}
\hline & $\mathrm{N}$ & Mean & Std. Deviation & \multicolumn{2}{|c|}{ Skewness } & \multicolumn{2}{|c|}{ Kurtosis } \\
\cline { 2 - 8 } & Statistic & Statistic & Statistic & Statistic & Std. Error & Statistic & Std. Error \\
\hline Product information & 266 & 2.72 & .936 & .548 & .149 & -.187 & .298 \\
Social role/image & 266 & 2.73 & .699 & .484 & .149 & .075 & .298 \\
Hedonic/pleasure & 266 & 3.17 & .840 & .157 & .149 & -.625 & .298 \\
Falsity/no sense & 266 & 2.42 & .610 & .597 & .149 & .697 & .298 \\
Valid N (listwise) & 266 & & & & & & \\
\hline
\end{tabular}

Table 4 presents the mean values, standard deviation (SD), skewness and kurtosis values of political advertising perceptions dimensions rated by the respondents from their experiences with political advertising on the social media. From Table 4, the mean scores of advertising beliefs ranged from 2.41 to 2.78 and standard deviation from 0.63 to 0.91 . Hedonic/pleasure dimension recorded the highest overall mean score of 2.78 and standard deviation of 0.91 . The skewness and kurtosis values were also presented in Table 4 and indicated non-violation of the normality assumption. As a general rule, therefore, the data for advertising belief dimensions do not need any transformation.

Table 4: Political advertising on the social media scores

\begin{tabular}{|l|c|c|c|c|c|c|c|}
\hline & $\mathrm{N}$ & Mean & Std. Deviation & \multicolumn{2}{|c|}{ Skewness } & \multicolumn{2}{|c|}{ Kurtosis } \\
\cline { 2 - 8 } & Statistic & Statistic & Statistic & Statistic & Std. Error & Statistic & Std. Error \\
\hline Product information & 266 & 2.41 & .805 & .525 & .149 & .252 & .298 \\
Social role/image & 266 & 2.52 & .703 & .259 & .149 & -.090 & .298 \\
Hedonic/pleasure & 266 & 2.78 & .906 & .052 & .149 & -.448 & .298 \\
Falsity/no sense & 266 & 2.43 & .625 & .303 & .149 & .118 & .298 \\
Valid N (listwise) & 266 & & & & & & \\
\hline
\end{tabular}

\subsection{Analysis of Variance based on location}

A one-way between-groups analysis of variance was conducted to explore the impact of the locations of voters on levels of perceptions of political advertising in printed media, on television and on the social media. The perceptions measured were product information (PI), social role/image (SR), hedonic/pleasure (HP) and falsity/no sense (FN). Subjects were 
divided into three groups according to their current location (city, surburban area and rural area or known as kampung). While most of the analyses showed non-significant results, however, there were two surprising findings revealed. The first finding was as follows:

Table 5: ANOVA: Total hedonic/pleasure (HP) - Social media

\begin{tabular}{|l|c|c|c|c|c|}
\hline & Sum of Squares & df & Mean Square & F & Sig. \\
\hline Between Groups & 11.436 & 2 & 5.718 & 7.289 & .001 \\
Within Groups & 206.318 & 263 & .784 & & \\
Total & 217.754 & 265 & & & \\
\hline
\end{tabular}

As shown on Table 5, there was a statistically significant difference at the $p<.05$ level in HP scores for the three groups: $F(2,266)=7.3, p=.001$. Despite reaching statistical significance, the actual difference in mean scores between the groups was medium. The effect size, calculated using eta squared, was 0.05 . Post hoc comparisons using Tukey HSD test indicted that the mean score for rural area [kampung] voters $(M=3.03, S D=0.80)$ was significantly different from city area voters $(M=2.72, S D=0.93)$ and suburban area voters $(M=2.48, S D=0.92)$. City area voters did not differ significantly from suburban area voters.

Table 6: ANOVA: Total product information (PI) - Television

\begin{tabular}{|l|c|c|c|c|c|}
\hline & Sum of Squares & df & Mean Square & F & Sig. \\
\hline Between Groups & 6.955 & 2 & 3.478 & 4.059 & .018 \\
Within Groups & 225.338 & 263 & .857 & & \\
Total & 232.294 & 265 & & & \\
\hline
\end{tabular}

Finally, there was a statistically significant difference at the $p<.05$ level in PI scores for the three groups: $F(2,266)=$ 4.06, $p=.01$ (refer Table 6). The actual difference in mean scores between the groups was, however, quite small. The effect size was 0.03 . Post hoc comparisons using Tukey HSD test indicted that the mean score for rural area [kampung] voters $(M=2.52, S D=0.80)$ was significantly different from city area voters $(M=2.90, S D=0.98)$. Suburban area voters $(M=2.48, S D=0.92)$ did not differ significantly neither from city area nor rural area voters.

\subsection{Analysis of Variance based on race}

Another one-way between-groups ANOVA was conducted to explore the impact of race on levels of perceptions of political advertising in Malaysia. The perceptions measured were product information (PI), social role/image (SR), hedonic/pleasure (HP) and falsity/no sense (FN). Subjects were divided into four groups according to race (Malay, Chinese, Indian and other Bumiputras). Similar to the previous analyses, most of the analyses showed non-significant results except for the following results:

Table 7: ANOVA: Total falsity/no sense (FN) - Printed media

\begin{tabular}{|l|c|c|c|c|c|}
\hline & Sum of Squares & df & Mean Square & F & Sig. \\
\hline Between Groups & 9.301 & 3 & 3.100 & 10.061 & .000 \\
Within Groups & 80.124 & 260 & .308 & & \\
Total & 89.425 & 263 & & & \\
\hline
\end{tabular}

Shown in Table 7, there was a statistically significant difference at the $p<.001$ level in FN scores for three groups: $F$ (3, $264)=10.06, p=.001$. The actual difference in mean scores between the groups was medium which the effect size, calculated using eta squared, was 0.10. Post hoc comparisons using Tukey HSD test indicted that the mean score for Chinese voters $(M=2.84, S D=0.52)$ was significantly different from Malay voters $(M=2.34, S D=0.57)$ and other Bumiputra voters $(M=2.20, S D=0.43)$. Indian voters did not differ significantly from the rest. 
Table 8: ANOVA: Total falsity/no sense (FN) - Television

\begin{tabular}{|l|c|c|c|c|c|}
\hline & Sum of Squares & $\mathrm{df}$ & Mean Square & $\mathrm{F}$ & Sig. \\
\hline Between Groups & 8.235 & 3 & 2.745 & 7.960 & .000 \\
Within Groups & 89.662 & 260 & .345 & & \\
Total & 97.898 & 263 & & & \\
\hline
\end{tabular}

There was a statistically significant difference at the $p<.001$ level in FN scores for three groups: $F(3,266)=7.96, p=$ .001 (refer Table 8). The actual difference in mean scores between the groups was medium where the effect size was 0.08. Post hoc comparisons using Tukey HSD test indicted that the mean score for Chinese voters $(M=2.81, S D=0.52)$ was significantly different from Malay voters $(M=2.34, S D=0.61)$. Indian voters $(M=2.50, S D=0.37)$ and other Bumiputra $(M 2.26, S D=0.51)$ did not differ significantly from the rest.

Table 9: ANOVA: Total falsity/no sense (FN) - Social media

\begin{tabular}{|l|c|c|c|c|c|}
\hline & Sum of Squares & df & Mean Square & F & Sig. \\
\hline Between Groups & 2.898 & 3 & .966 & 2.503 & .05 \\
Within Groups & 100.327 & 260 & .386 & & \\
Total & 103.225 & 263 & & & \\
\hline
\end{tabular}

There was a statistically significant difference at the $p<.05$ level in FN scores for three groups: $F(3,264)=2.50, p=.05$ (refer Table 9). The actual difference in mean scores between the groups was small. The effect size, calculated using eta squared, was 0.03 . Post hoc comparisons using Tukey HSD test indicted that the mean score for Chinese voters $(M=$ 2.67, $S D=0.63)$ was significantly different from Malay voters $(M=2.39, S D=0.62)$. Other groups did not differ significantly from the rest.

\section{Discussion}

On the whole, the difference in the perceptions of political advertising between Malaysia voters who lived in either the city area, suburban area or the rural area was fairly negligible. In most cases, the respondents somewhat agreed to the role of these three media in delivering information about the political parties as well as the candidacy. They also somewhat agreed about the role of political advertising in these media in reflecting their image in the society. Surprisingly, they also slightly agreed about the inaccuracy of political advertising delivered through all the three media.

However, a closer look at the roles of advertising media found a slight divergence. For example, the 'kampung' voters felt that political advertising on the social media as not as entertaining as the rest of the respondents did. In spite of much media hype has been promulgated about political advertising on the social media (Berita Harian, 2012); some voters thought it has no effect in engaging them in the political issues discussed. Although at this point any conclusion may be uncertain, the intensive use of the social media during the election can be seen as a waste, especially the respondents also barely agree to the role of this medium in delivering truthful information about political issues and candidacy.

Secondly, the study observed an unusual remark where there was a significant different between the 'kampung' voters and the city and suburban area voters as regard to their perceptions toward the ability of political advertising on the television to deliver knowledge about political issues. It was found that 'kampung' voters were not as convinced as the city dwellers in believing what they watch about political issues on the television. Although the study does not substantiate positive consumer-television advertising relationship, it does develop relationships with political advertising on the television through a greater understanding of political parties and candidacy. This is consistent with Hirschman and Thompson's (1997) theory that consumers use various interpretive strategies (in this case, identifying and individualizing strategies) to interpret images and meanings advertised in the media that could have an impact leading to the formation of attitudes towards advertising in specific media (in this case, on political advertising on the television).

Finally, there was a pattern of differences, especially among Chinese and Malay voters, in their perceptions of political advertising as a source of manipulation, exaggeration or misleading information, in all three media. Generally, Chinese voters were more doubtful about the political information delivered through the media, albeit their agreement the overall falsity/no sense statements. Previous study also found a minor issue, especially, with internet advertising as a 
source of believable information (Yaakop, A. \& Hemsley-Brown, J. 2012). Although there is no immediate explanation for this scenario, it obviously shows that the voters are quite cautious with the materials the read and watch on these media.

\section{Limitations of the Research}

Firstly, the sample used in this research was a specific limited-parent population group; therefore, generalization of the findings for populations beyond the sample utilised would account for a research bias. The sample of this study was limited to Malaysian citizens who were exposed to political advertising during a one-month period after the dissolution of the Parliament. Although several statistical tests have been carried out to demonstrate homogeneity of the sample across different demographic backgrounds, it should be cautioned that the results must be viewed in the light of the sample employed. One should be careful when interpreting the results of this study because it is possible that advertising attitude patterns of other consumers from diverse interest backgrounds will be different from what was discovered in this study.

Finally, the scope of the research was limited to examining attitudes towards political advertising from three different media frames of reference, i.e. print, television and the social media. The decision to include only these three advertising media was made purposely to serve the context of Malaysia's political scene in which these three media have been given greater emphasis to propagate political issues in Malaysia. However, with rapid advancement in mass media technology, the birth of modern-day media is inevitable and the use of each of these media should bear equal importance in many facets of consumerism. In the future, more research like this is deemed necessary, especially in examining public attitudes toward advertising via specific and new advertising media.

\section{References}

Alwitt, L. F. and Prabhaker, P. R. (1992), "Functional and Belief Dimensions of Attitudes to Television Advertising", Journal of Advertising Research, 32 (5), 30-42.

Ambler, T. (2000), "Persuasion, Pride and Prejudice: How Ads Work", International Journal of Advertising, 19(3), 299-315,

Ansolabehere, S., \& lyengar, S. 1995. Going negative: How political advertisements shrink and polarize the electorate. New York: Free Press.

Atkin, C. K., \& Heald, G. (1976). Effects of political advertising. Public Opinion Quarterly, 40(2), 216-228.

Berita Harian (2012), retrieved on 4 February 2014 from http://www.bharian.com.my/bharian/articles/PRU13jadi_8216 _pilihanrayamediasosial__8217_/m/mArticle

Brackett, L. K. and Carr, B. N. Jr. (2001), "Cyberspace Advertising vs. Other Media: Consumer vs. Mature Student Attitudes", Journal of Advertising Research, (Sept/Oct), 23-32.

Colley, R. H. (1961), Defining Advertising Goals for Measured Advertising Results. New York: Association of National Advertisers.

Ducoffe, R. H. (1996), "Advertising Value and Advertising The Web", Journal of Advertising Research, 36(5), 21-35.

Greening, D. W., \& Gray, B. (1994). Testing a model of organizational response to social and political issues. Academy of Management Journal, 37(3), 467-498.

Hirschman, E. C. and Thompson, C. J. (1997), "Why Media Matter: Toward a Richer Understanding of Consumer' Relationships with Advertising and Mass Media", Journal of Advertising, 26(1), 43-60.

Jamieson, K.H. \& Campbell, K.K.: The Interplay of Influence: News, Advertising, Politics, and the Mass Media: Retrieved 05 September 2000) Key: citeulike:400359

Kahn, K. F., \& Geer, J. G. (1994). Creating impressions: An experimental investigation of political advertising on television. Political Behavior, 16(1), 93-116.

Kaid, L. L. (2002). Political advertising and information seeking: Comparing exposure via traditional and Internet channels. Journal of Advertising, 31(1), 27-36.

Kaid, L. L., \& Sanders, K. R. (1978). Political television commercials: An experimental study of the type and length. Communication Research, 5(1), 57-70.

Kaid, L. L., Chanslor, M., \& Hovind, M. (1992). The influence of program and commercial type on political advertising effectiveness. Journal of Broadcasting and Electronic Media, 36(3), 303-320.

La Ferle, C., Edwards, S. M., and Lee. W. (2000), "Teend' Use of Traditional Media and the Internet", Journal of Advertising Research, 40(3), 55-65.

Lei, R. M. (2000), "An Assessment of the World Wide Web as an Advertising Medium", Social Science Journal, 37(3), 465-471.

Leong E. K. F., Huang, X., and Stanners, P. (1998), "Comparing the Effectiveness of the Web Site with Traditional Media", Journal of Advertising Research, (Sept/Oct), 44-51.

Petrovici, D. and Marinov, M. (2007), "Determinants and Antecedents of General Attitudes towards Advertising", European Journal of Marketing, 41(3/4), 307-326.

Petty, R. E. and Cacioppo, J. T. (1986), "The Elaboration Likelihood Model of Persuasion", Advances in Experimental Social Psychology, 19.

Political election advertising: What is Political advertising. Retrieved November 22, 2013 from advertising Standard Bureau web site: 
www.adstandard.com.au/process/theprocessteps

Pollay, R. W. (1986), "The Distorted Mirror: Reflections on the Unintended Consequences of Advertising", Journal of Marketing, 50(Apr), 18-36.

Pollay, R. W. (1987), "On the Value of Reflections in 'The Distorted Mirror"', Journal of Marketing, 51(Jul), 104-109.

Quily, P. (2008). Barack Obama vs. John McCain social media and search engine scorecard. Retrieved May 1, 2010, from http://adultaddstrengths.com/2008/11/05/obama-vsmccain- social-media/

Ratnam, K. J., \& Milne, R. S. (1970). The 1969 Parliamentary Election in West Malaysia.Pacific Affairs, 43(2), $203-226$.

Rawlinson, L. (2007). Will the 2008 USA election be won on Facebook? Retrieved May 1, 2010, from http://www.cnn.com/2007/TECH/05/01/election.facebook/

Rossiter, J. R. and Percy, L. (1996), Advertising Communications and Promotion Management, New York: McGraw-Hill.

Sandage, C, H. and Leckenby, J. D. (1980), "Student Attitudes toward Advertising: Institution vs. Instrument", Journal of Advertising, 9(2), 29-54.

Schlosser, A. E. and Shavitt, S. (1999), "Survey of Internet Users' Attitude Toward Internet Advertising", Journal of Interactive Marketing, 13(3), 34-54.

Shavitt, S., Lowrey, P., and Haefner, J. (1998), "Public Attitudes Toward Advertising: More Favourable Than You Might Think", Journal of Advertising Research, (Jul/Aug), 7-22.

Smith, A. (2009). The Internet's role in campaign 2008. Pew Internet \& American Life Project. Retrieved May 12, 2010, from http://pewinternet.org/Reports/2009/6-The-Internets-Rolein- Campaign-2008.aspx

Tinkham, S. F., \& Weaver-Lariscy, R. A. (1993). A diagnostic approach to assessing the impact of negative political television commercials. Journal of Broadcasting and Electronic Media, 37(4), 377-400.

Valentino, N. A., Hutchings, V. L., \& Williams, D. (2004). The impact of political advertising on knowledge, Internet information seeking, and preference. Journal of Communication, 54(2), 337-354.

Vitak, J., Smock, A., Zube, P., Carr, C., Ellison, N., \& Lampe, C. (2009, May). "Poking" people to participate: Facebook and political participation in the 2008 election. Paper presented at the 2009 Annual Meeting of the International Communication Association, Chicago, IL.

Yaakop, A. Y., HemsleyBrown, J. \& Gilbert, D. C. (2011). Attitudes towards Advertising: Malaysians vs Non Malaysians. Asian Journal of Business and Management Sciences, 1(2),77-94.

Yaakop, A. Y., Anuar, M. M. \& Omar, K. (2013). Like it or not: Issue or credibility in Facebook advertising. Asian Social Science. 9 (3), 154-163. 